ployed in a noisy boiler factory. Most of them were boiler makers. Among the findings there was a fact worthy of particular notice. It was namely interesting to find among $\mathbf{1 5}$ cases, each having a unilateral large perforation, 5 cases, who showed lesser grade of deafness for high tones on the perforated side than on the opposite where the ear drum was intact.

This finding suggests that the inner ear deafness due to noise is chiefly brought about by sound impact transmitted via the ear drum.

\title{
ON THE INFLUENCE OF THE FENESTRATION OPERATION OF THE LABYRINTH ON THE COCHLEAR ELECTRIC "RESPONSE
}

By

T. KASHIWADO, G. IINO,

T. TOKUNAGA and W. OOHASHI

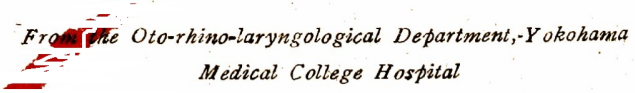

$I=$ IS.A. the fenestration operation of the labyrinth is said to have contributei a remarkable progress in the treatment of clinical otosclerosis, mainly due to the efforts of Lempert and others. So we intended to examine the effect of the operation by animal experiments. The cochlear electrical response of Wever and Bray is reported to become reduced or disappear by lesion of the eardrum or the middleear ossicles (Crowe and Hughson). If the fenestration operation of the labyrinth improves the hearing of the otosclerosis patient. Wever-Bray's cochlear electric response operatively reduced or abolished is expected to be enhanced or reappear by the fenestration operation. Along this line of consideration the authors made some experiments on cats and guinea-pigs and confirmed the expectation.

When, namely, the eardrum, malleus and incus were excisad, and round and oval windows were closed with vaselin in animals, the cochlear response of Wever and Bray became reduced or abolished, which, however, was made enhanced or reappear, when further fenestration operation was carried out on the side wall of the basal coil of the cochlea.

The authors regard this experiment as a corroboration on the effectiveness of fenestration in improving the hearing of some patients of clinical otosclerosis. 